\title{
The Challenge of Expanding the Boundaries of Heart Transplantation in Argentina
}

\author{
El desafío de extender los límites del trasplante cardíaco en la Argentina
}

CÉSAR A. BELZITI ${ }^{1}$ (D) , RICARDO G. MARENCHINO² (D)

\section{INTRODUCTION}

More than 50 years have passed since the first human heart transplant (HTx) was performed, becoming the treatment of choice for end-stage heart failure.

Despite advances in ventricular assist devices, longterm results encourage the use of transplantation, and over 140,000 HTxs had been reported worldwide as of June 2017.

Indication for transplantation has been consolidated, and there is consensus that it should be performed in patients with symptoms of advanced heart failure, poor short-term prognosis, and no alternative treatment possibilities.

\section{SITUATION OF HEART TRANSPLANTATION IN THE WORLD}

\section{AND IN ARGENTINA}

In the latest Registry of the International Society for Heart and Lung Transplantation (ISHLT), 5,149 HTxs, $88 \%$ of which were in adult recipients, were reported in the period extending from July 1, 2016 to June 30, 2017. Compared with 2000, the number of HTxs increased by more than 1000 cases/year, as reported by 330 adult and 212 pediatric HTx centers. (1) It is difficult to ensure whether the increase is real because registration was voluntary, but has become mandatory in recent years in some countries, such as Argentina, where the information is directly submitted by the Central Unique National Institute Coordinator of Ablation and Implant (INCUCAI).

Data provided by Argentina were submitted by 20 HTx centers. The number of HTxs in Argentina is, with small fluctuations, around 100-110 HTxs per year. (2) The first question is whether this number is enough to meet the needs of advanced heart failure patients in our country. There are two ways of responding to this point; one is by referring to statistics from other countries, such as the Spanish National Transplant Organization (ONT), which reports that 6 HTxs are needed per million population (pmp) per year. Argentina, with 44 million inhabitants, would need 264 HTxs per year, which is barely above $40 \%$ of the desired number. (3) Another less theoretical and perhaps harsher response is to know that in Argentina, $25 \%$ of patients on the waiting list die before having access to transplantation. (4)

\section{NEW INDICATION FOR HEART TRANSPLANTATION}

Another situation that makes the number of required HTxs even more distant from those performed is the extension of the indication to recipients who were considered non-eligible for transplantation a few years ago. For example, the limiting age was 55 a few decades ago, and is now around 70 .

Also, in cases of systemic diseases -such as Chagas disease, which was a contraindication due to the risk of relapses- transplantation became a common indication due to the pioneering experiences of several centers in South America, particularly Brazil. (5)

Both amyloid light chain (AL) and transthyretin (TTR) amyloidosis has followed the same trend: from absolute contraindication to mandatory indication in cases of significant cardiac involvement, though it requires a special approach with specific drugs and in many cases with bone marrow transplantation. (6)

\section{Abbreviations}

AHTx Heart transplant

ISHLT International Society for Heart and Lung Transplantation

HIV Human immunodeficiency virus
ECMO Extracorporeal membrane oxygenation

DBD Donor after brain death

DCD Donor after circulatory death 
Human immunodeficiency virus (HIV) infection was associated with poor short-term prognosis. With the advent of highly active antiretroviral therapy (HAART), the disease has become chronic and survival has improved significantly. HIV-associated cardiomyopathy, which was a contraindication due to poor prognosis of the underlying disease, is now considered an appropriate indication for selected patients. The first HTx in Latin America was reported in Argentina. Clearly, performing heart transplantation in this entity requires a multidisciplinary approach. (7) Another similar example is cardiac involvement in other systemic diseases, such as sarcoidosis. (8)

Indication for heart transplantation in patients with adult congenital heart disease represented a very small percentage of the etiologies, but in recent years, it has reached $3 \%$ of total HTxs, and $11 \%$ in adults aged 18 to 39 years. This is the result of improved treatments for children with congenital heart disease that allow them to reach adulthood. Heart transplantation in adult congenital heart disease requires special knowledge and expertise, since all patients have a history of several surgical procedures, which implies facing a very complex surgery, with high immunological risk due to possible receptor hypersensitivity. This is one of the groups with higher in-hospital mortality after retransplantation, but with the highest survival rate after the post-transplant period. (1) Retransplantation is rare, but its indication has increased for young people who underwent HTx in childhood or adolescence and who present with graft failure years later, as evidenced by the fact that retransplantation represents $7 \%$ among recipients aged 18 to 39 years. (9)

Multiorgan transplants are another growing group, especially the heart-kidney transplant, representing $85 \%$ of this population. This combination represents less than $3 \%$ of HTxs, but it is over $12 \%$ in patients requiring retransplantation. This situation occurs in HTx patients who have developed graft deterioration by different mechanisms, such as episodes of rejection or graft vessel disease, and who also present with severe kidney failure, usually by the prolonged use of immunosuppressive calcineurin inhibitors. (1)

Registries from the United States of America show that cancer mortality rates continue to decline. This effect has been verified for most types of cancer and in all ethnic groups. However, it is known that both drugs and radiotherapy can cause heart injury, and a group of patients may have advanced heart failure. The combination of longer life expectancy and myocardial injury has increased the indication of heart transplantation in neoplasm survivors. (10)

Again, as in other conditions mentioned above, survival improvement results in potential candidates for HTx.

This scenario is reflected in ISHLT registries, showing that the characteristics of receptors have varied over the years. Comparing by decade, from
1980 to the present, recipients are older, they increasingly have a history of one or more heart surgeries, and have more comorbidities, such as hypertension, smoking, pulmonary disease, obesity, and history of neoplasms. (11)

A registry from a center in Argentina comparing the characteristics of HTx recipients in two periods -the first from 1993 to August 2003 and the second from September 2003 to 2014- agrees with the change of recipient profile. In the most recent series, recipients had increased body mass index, higher prevalence of Chagas disease and pulmonary hypertension, and more often arrived for urgent surgery with inotropic support or with intra-aortic balloon pump counterpulsation in a state of emergency. (12) It is then clear that we need to increase the number of HTx, so in addition to the contributions from campaigns to promote organ donation and the changes in legislation, medical groups should have technological resources and implement specific strategies to bring heart transplantation to more patients with advanced heart failure.

\section{LONG-TERM CIRCULATORY SUPPORT}

As a result of donor shortage, long-term circulatory support has been developed for any of its indications: as bridge to transplantation, to decision-making, to candidacy or as destination therapy.

The use of devices to replace cardiac function has been approved for clinical use since the $90 \mathrm{~s}$, and there are records of over 22,000 implants, with patient recruitment from 2006 to the present time. (13) According to the latest ISHLT registry, $50 \%$ of patients reach transplantation with a ventricular assist device, mainly continuous-flow devices for prolonged univentricular support. Use of short-term assist devices [extracorporeal membrane oxygenation (ECMO) or centrifugal pumps] as direct bridge to transplantation is rare and associated with high mortality. (1)

Unfortunately, the use of these devices in Argentina has not been widespread. Long-term circulatory support implantation is restricted to programs in pediatrics, with the use of pulsatile pumps and sporadic implants in adults. This reality is due to the high cost of this type of technology, making it very difficult for public health insurance plans to accept it. For years, this situation has remained unchanged, despite individual and joint efforts by transplant teams and physicians involved in the management of heart failure, and it seems difficult to be changed today.

The concern lies in that the management of patients with advanced heart failure in Argentina differs from developed countries due to lack of access to circulatory support, so we are several years behind in the options we can offer these patients. It is also surprising that the cardiology community - ever aiming to be at the same level of international practice in many high-cost interventions such as transcatheter aortic valve implantation, use of mitral valve clips, etc.- does 
not seem to be too affected by the lack of access to circulatory support. This last point forces us to reflect upon the physicians' attitude regarding transplantation and end-stage heart failure by asking ourselves whether there is really awareness or interest in encouraging the practice or conviction of the benefits it can offer their patients. This attitude is also reflected in the low levels of organ procurement -an issue the new transplant law is trying to improve.

Recent changes in the transplant law include a series of measures aimed at increasing the donor pool by keeping the figure of presumed donor more strongly than in the previous law, creating procurement units and generating a series of measures to speed up the donation-transplant process. We hope organ procurement will increase, but its true impact remains to be seen.

\section{HEART PRESERVATION SYSTEMS AND DONOR AFTER CIRCULATORY DEATH}

The other way in which the world has responded to the shortage of organs for transplantation is through the use of continuous perfusion systems for organ protection, opening the door to the use of suboptimal donors, longer transfers with long ischemic times, and eventually to the use of non-heart-beating donors. In brief, deceased donors with categorically determined brain death but maintaining cardiac activity, termed donor after brain death (DBD) are used for heart transplantation. In recent years, organs from donors after circulatory arrest, called donor after circulatory death (DCD) have been used. The use of these donors for kidney, liver, lung, and pancreas transplantation has increased. For instance, the International Society for Heart and Lung Transplantation (ISHLT) registry reported 3,992 lung transplants using DBD and 306 using DCD within the period 2003-2013, with similar results of hospital, one-year, and five-year survival rates. (14) In the UK Registry, the number of organ donors increased from 12.0 to 18.3 pmp from 2003 to 2012. This increase has been predominantly the result of a rise in DCD from 1.1 to $7.9 \mathrm{pmp}$, while the numbers of DBD remained stable, around $10.5 \mathrm{pmp}$. Survival was similar for DCD or DBD. This registry includes kidney, lung, liver and pancreas transplants but does not report any HTxs. (15) Experience with DCD for heart transplantation is limited and refers to case reports from Australia and England. (16)

Based on the Maastricht classification, DCD are categorized as follows: I. patients with cardiac arrest, without cardiopulmonary resuscitation (CPR); II. circulatory arrest with uncontrolled CPR; III. "awaited" cardiac arrest due to withdrawal of life-sustaining therapies; IV. DBD patients who have a cardiac arrest; and V. euthanasia. Maastricht category III donors have been used for HTx. (17) The method requires changes in legislation to implement the procedure and family agreement for withdrawal of life-sustaining therapies. In addition, expensive technology is re- quired to recover the heart from the metabolic and functional disorders caused by circulatory arrest. For this purpose, the excised heart must be connected to a device that provides continuous perfusion for several hours and allows the "ex vivo" heart recovery. This device preserves the organ during transportation to the hospital where the transplant will be performed. (18) For these reasons, the progress of this method for heart transplantation is slow, but it undoubtedly represents a contribution to narrowing the gap between donors and patients on the waiting list.

\section{SUBOPTIMAL DONORS}

In the light of all the above, one element that is available and can be used to push the boundaries in the number of HTx is the use of suboptimal donors. These donors, while acceptable as such, may have greater probability of graft dysfunction or poorer results compared with ideal donors. Examples of suboptimal donors are those over 40, women when the recipient is male, donors with history of resuscitated cardiac arrest, or with inotropic support or any other relevant history.

This change has been experienced worldwide and is evident in the ISHLT registries. When analyzing donors according to the transplantation decade, donors of recent years present some characteristics that remove them from the optimal donor, as older age, more comorbidities and longer ischemic times. However, these changes have not had a negative impact, and current survival curves have even improved compared with earlier decades. These results probably reflect the progress in other aspects, such as immunosuppressive treatment, infection and intraoperative management. and certainly transplant team training $(19,20)$ The use of these organs will be decided by the transplant teams depending on the level of urgency or clinical condition of the recipient, their position regarding the use of this type of donor, and most important, the experience of the medical team to face a situation of greater risk. (21)

\section{CONCLUSIONS}

The difficulties for expanding HTx in Argentina are multifactorial, which in part is common to all transplant centers in the world, but it is also due to a local difficulty to have access to technological resources, such as complex circulatory support and organ preservation systems. Joint action of the authorities and the medical community is required to successfully overcome this challenge

Conflicts of interest

None declared.

(See authors' conflicts of interest forms on the website/ Supplementary material).

Ethical considerations

Not applicable 


\section{REFERENCES}

1. Kush K, Cherikh W, Chambers D, Goldfarb S, Hayes D, Kucheryavaya A, et al. 2018; The International Thoracic Organ Transplant Registry of the International Society for Heart and Lung Transplantation: Thirty-fifth Adult Heart Transplantation Report-2018; Focus Theme: Multiorgan Transplantation. J Heart Lung Transplant 2018;37:1155-68. http:// doi.org/10.1016/j.healun.2018.07.022

2. Central de Reportes y Estadisticas CRESI. INCUCAI. www.incucai.gov.ar

3. Organización Nacional de Trasplantes. www.ont.es

4. Sistema Nacional de Información SINTRA.INCUCAI. www.incucai.gov.ar

5. Bocchi EA, Fiorelli AI. The paradox of survival results after heart transplantation for cardiomyopathy caused by Trypanosoma cruzi. First Guidelines Group for Heart Transplantation of the Brazilian Society of Cardiology Ann Thorac Surg 2001;71:1833-8. http:// doi. org/10.1016/s0003-4975(01)02587-5

6. Belziti C, Bagnati R, Torres Bianqui C, Arbelbide J, Nucifora E, Domenech A, et al. Trasplante cardíaco y de médula ósea en un paciente con amiloidosis AL e insuficiencia cardíaca refractaria. Rev Argent Cardiol 2009;77:309-311.

7. Mouras P, Barcán L, Belziti C, Pizarro R, Mañez N, Marenchino R. Trasplante cardíaco en paciente infectado con el virus de inmunodeficiencia humana. Medicina (B Aires). 2017;77:509-11.

8. Belziti CA, Maldonado S, Vulcano N, Perez de Arenaza D, Marenchino R, Domenech A, et al. Sarcoidosis cardíaca: trasplante cardíaco y recidiva de la enfermedad. Rev Argent Cardiol 2010;78:358-60.

9. Lund L, Edwards L, Kacheryavaya A, Benden Ch, Christie J, Dipchand A et al. The registry of the International Society for Heart and Lung Transplantation: thirty-first official adult heart transplant report-2014; focus theme: retransplantation. J Heart Lung Transplant 33:996-1008. http://doi.org/10.1016/j.healun.2014.08.003

10. Edwards BK, Noone AM, Mariotto AB, Simard EP, Boscoe FP, Henley SJ, et al. Annual Report to the Nation on the status of cancer, 1975-2010, featuring prevalence of comorbidity and impact on survival among persons with lung, colorectal, breast, or prostate cancer. Cancer 2014;120:1290-314. http://doi.org/10.1002/ cncr.28509

11. Stehlik J, Chambers D, Zuckermann A, Mehra M, Khlush K. Increasing complexity of thoracic transplantation and the rise of multiorgan transplantation around the world: Insights from the
International Society for Heart and Lung Transplantation Registry. J Heart Lung Transplant;37:1145-54. http:// doi.org/10.1016/j. healun.2018.07.016

12. Peradejordi Lastras MA, Favaloro LE, Vigliano C, Renedo MF, Martinez L, Moscoloni SE, et al. Resultados del Trasplante Cardíaco según el perfil clínico del receptor: 21 años de experiencia. Rev Argent Cardiol 2016;84:235-41.

13. Kirklin J, Pagani F, Kormos R, Stevenson L, Blume E, Myers S, et al. Eighth annual INTERMACS report: Special focus on framing the impact of adverse events. J Heart Lung Transplant 2017;36:1080-6. http:// doi.org/10.1016/j.healun.2017.07.005

14. Cypel M, Levvey B, Van Raemdonck D, Erasmus M, Dark J, Love R et al. International Society for Heart and Lung Transplantation Donation After Circulatory Death Registry Report. J Heart Lung Transplant 2015;34:1278-82. http://doi.org/10.1016/j. healun.2015.08.015

15. Johnson RJ, Bradbury LL, Martin K, Neuberger J; UK Transplant Registry. Organ donation and transplantation in the UK-the last decade: a report from the UK national transplant registry. Transplantation 2014;97 Suppl 1:S1-S27. http:// doi.org/10.1097/01. TP.0000438215.16737.68

16. Dhital KK, Iyer A, Connellan M, Chew H, Gao L, Doyle A, et al. Adult heart transplantation with distant procurement and exvivo preservation of donor hearts after circulatory death: a case series. Lancet 2015;385:2585-91. http://doi.org/10.1016/S01406736(15)60038-1

17. Evrard P, Belgian Working Group on DCD National Protocol. Belgian modified classification of Maastricht for donors after circulatory death. Transplant Proc 2014;46:3138-42. http://doi.org/10.1016/j. transproceed.2014.09.169

18. Knop G. Trasplante cardíaco con donantes cadavéricos: de la investigación a la práctica clínica. Rev Argent Cardiol 2016;84:59-63.

19. Madan O, Saeed P, Vlismas I, Katsa F, Patel J, Shin D. Outcomes for Donors Heart with low ejection fraction that improve with donor management. J Heart Lung Transplant 2017;36:S27. https://doi. org/10.1016/j.healun.2017.01.287

20. Berg K. Survival and Graft Function in Heart Transplant Patients Receiving Adverse Risk Profile Donor Heart. J Heart Lung Transplant 2018;37:S161. https://doi.org/10.1016/j.healun.2018.01.415

21. Klush K, Ball R. Great Variability in Donor Heart Acceptance Practice Across the United States. J Heart Lung Transplant 2017;36:S127. https://doi.org/10.1016/j.healun.2017.01.329 